Supporting information

One-step Fabrication of Micro/nanosphere-coordinated Dual Stimulus-responsive Nanofibrous Membrane for Intelligent Antifouling and Ultrahigh Permeability of Viscous Water-in-oil Emulsion

Yajie Ding ${ }^{1}$, Shuting $\mathrm{Xu}^{1}$, Huiling Zhang ${ }^{1}$, Jiaming Zhang ${ }^{1}$, Zhiye Qiu ${ }^{1}$, Huaxiang Chen ${ }^{1}$, Jiping Wang $^{2}$, Jinhuan Zheng ${ }^{1}$, Jindan $\mathrm{Wu}^{1 *}$

${ }^{1}$ Engineering Research Center for Eco-Dyeing \& Finishing of Textiles, Ministry of Education, Zhejiang Sci-Tech University, Hangzhou 310018, Zhejiang, PR China;

${ }^{2}$ Shanghai University of Engineering Science, Shanghai 200336, PR China;

*Correspondence: wujindan@zstu.edu.cn; Tel.: +86-571-86843436 


\section{Supporting Figures:}
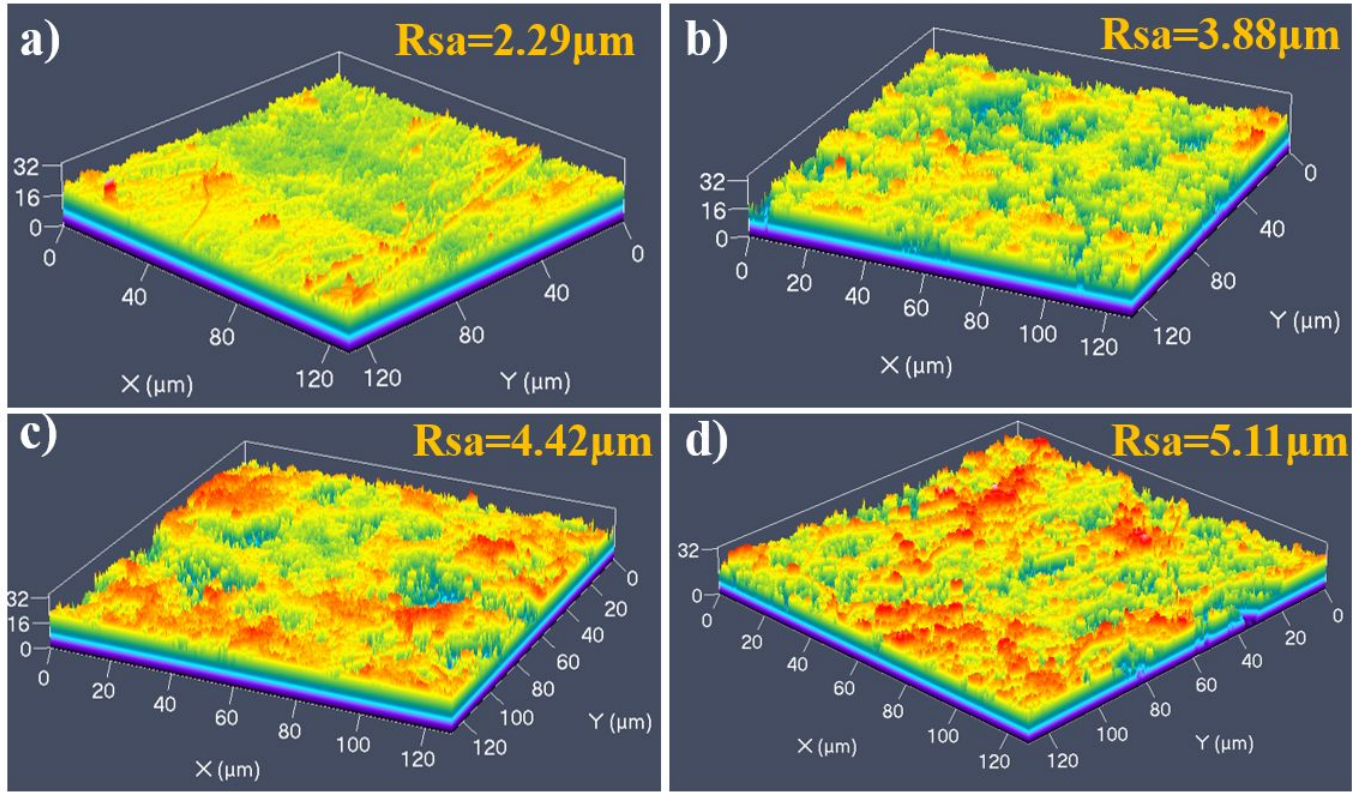

Fig S1. The roughness of the PVDF based nanofiber membranes: a) pristine PVDF membranes, b) M1; c) M2; d) M3 membranes. 


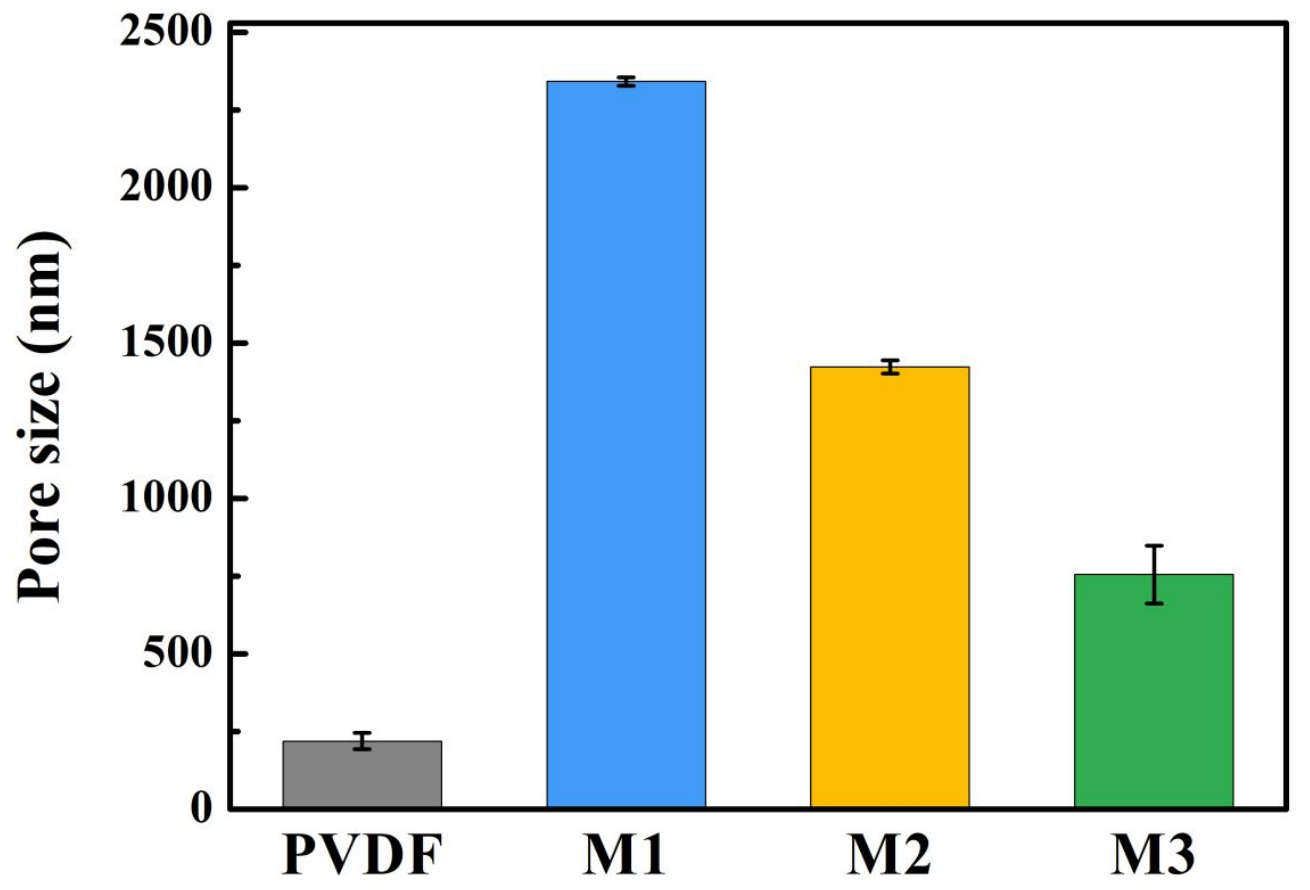

Fig S2. The pore size of corresponding membrane.
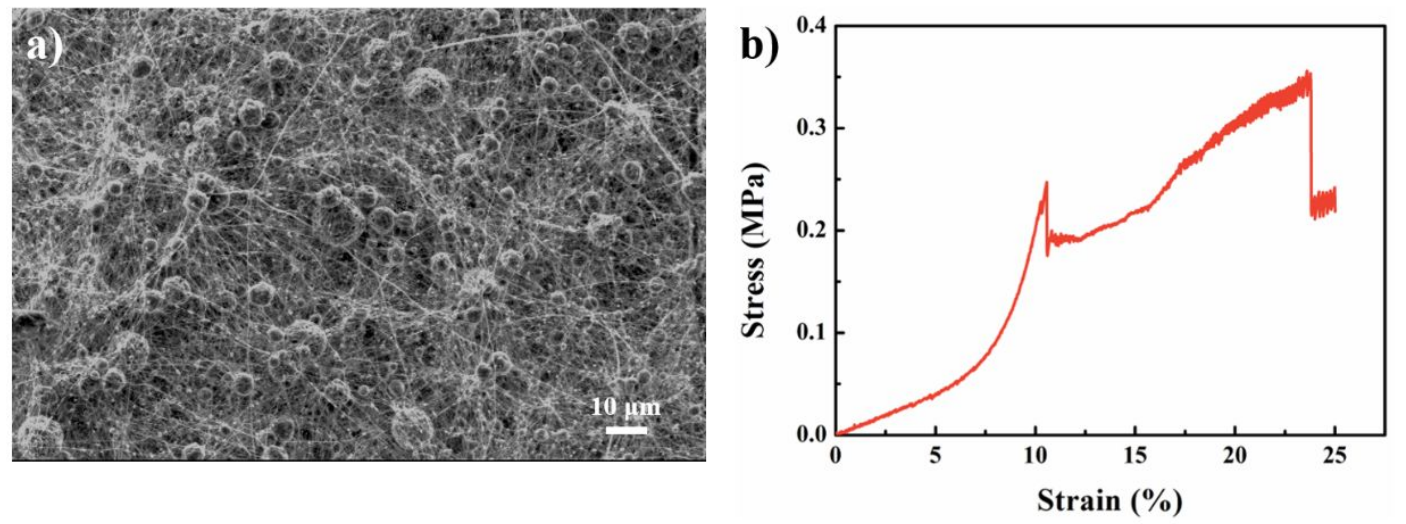

Fig S3. SEM image (a) and mechanical properties (b) of M3 after long time use. 

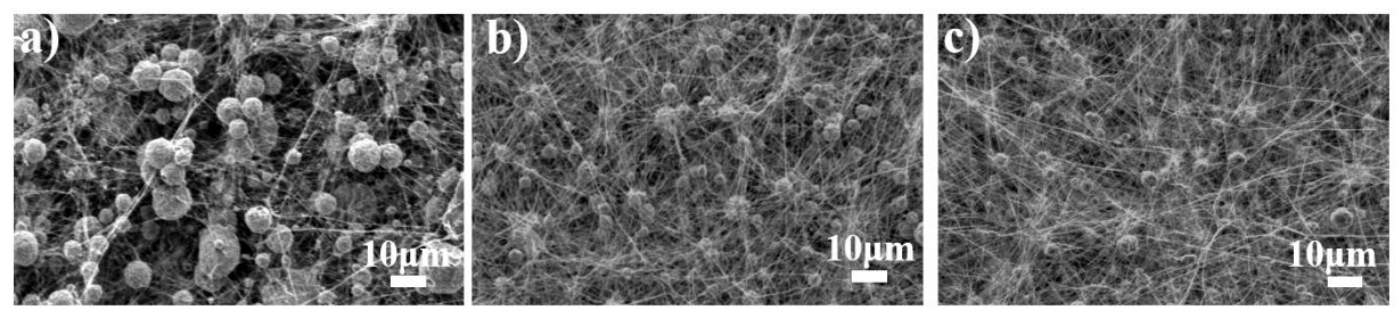

Fig S4. The SEM images of the membrane with PVDF:P(AN-co-AM) ratios of (a) 4:1, (b) 5:1 and (c) 6:1, respectively.

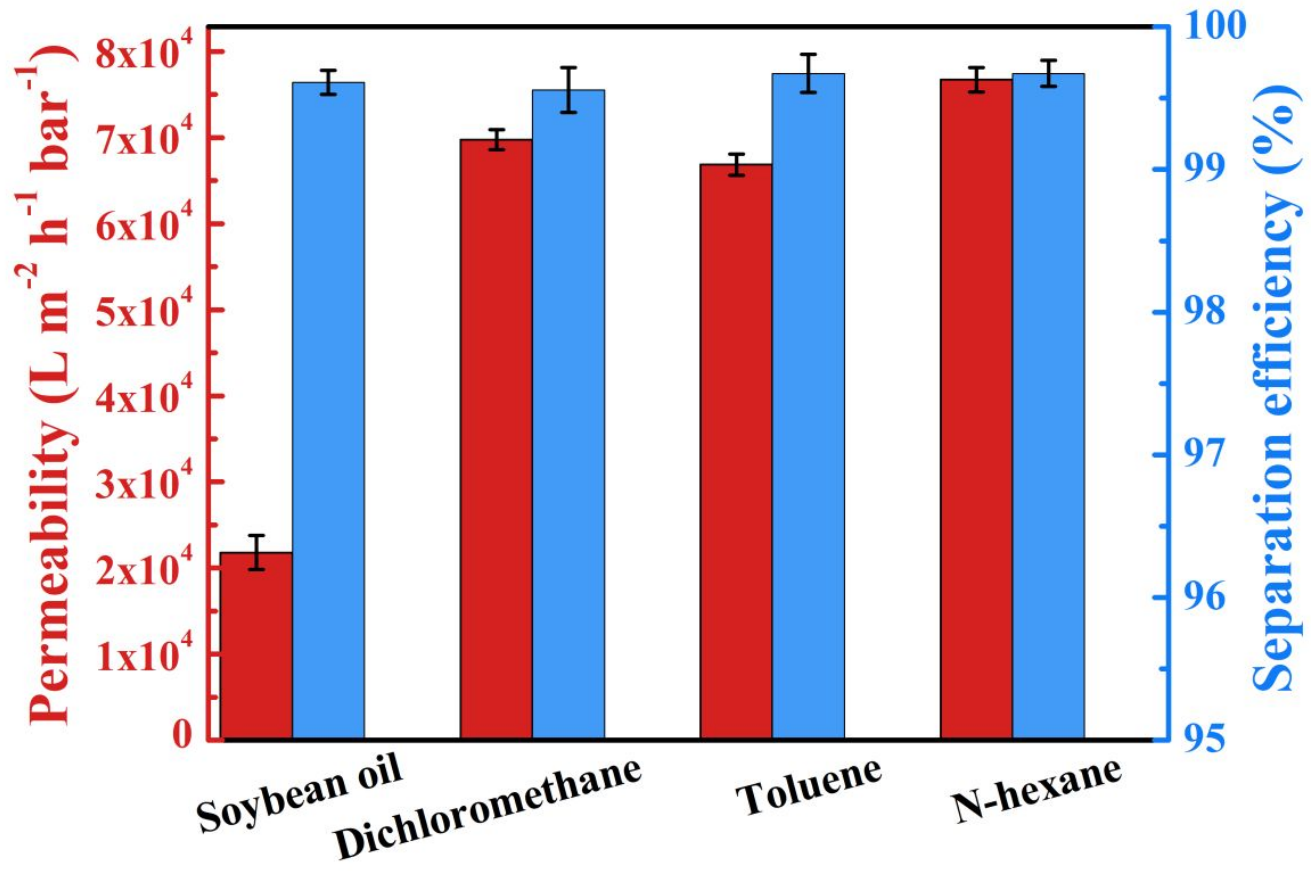

Fig S5. The separation performances for different emulsion using M3 membrane. 


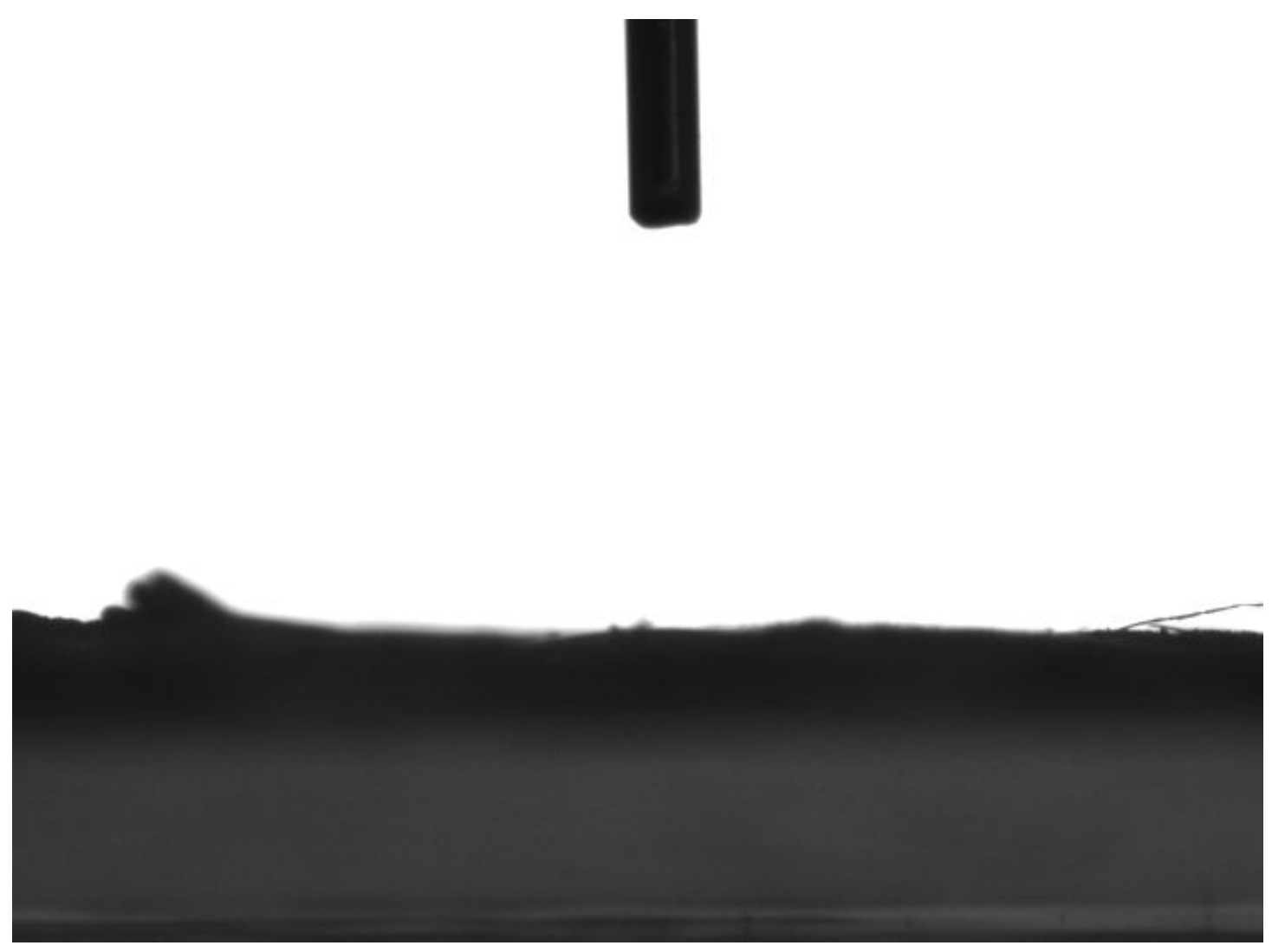

Fig S6. The contact angle of the M3 membrane under strong acid (pH 1), high temperature $\left(100^{\circ} \mathrm{C}\right)$ and salt solution $\left(1 \mathrm{~mol} \mathrm{~L}^{-1}\right)$ environment.

Supporting Video S1: The continuous oil jet contacted with the M3 membrane surface.

Supporting Video S2: The fouled M3 membrane was rinsed by acid water $(\mathrm{pH} 3)$ and high temperature $\left(55^{\circ} \mathrm{C}\right)$. 